\title{
The incidence of visual impairment and its determinants in the WHO multinational study of vascular disease in diabetes
}

\author{
E.Miki ${ }^{1}$, M.Lu ${ }^{2}$, E.T.Lee ${ }^{2}$ H.Keen ${ }^{3}$, P.H.Bennett ${ }^{4}$, D. Russell ${ }^{2}$ and the WHO Multinational Study Group* \\ ${ }^{1}$ 3-4-2, Matsunami, Chuo-Ku, Chiba-Shi 260, Japan \\ ${ }^{2}$ Centre for American Indian Health Research and Department of Biostatistics and Epidemiology, College of Public Health, \\ University of Oklahoma Health Sciences Centre, Oklahoma City, USA \\ ${ }^{3}$ Unit for Metabolic Medicine, Guy's Hospital, London, UK \\ ${ }^{4}$ Phoenix Epidemiology and Clinical Research Branch, NIDDK, Phoenix, Arizona, USA
}

\section{Abstract}

Aims/hypothesis. Incidence of severe visual impairment and the ultimate prevalence of all grades of impairment were estimated in the 10 centres of the WHO Multinational Study of Vascular Disease in Diabetes (WHO MSVDD) participating in the followup.

Methods. Visual function was ascertained at followup in $2994(77.9 \%)$ of the 3845 eligible participating survivors of the 4709 originally recruited for the WHO MSVDD using the same baseline enquiry method. The associations between incident severe visual impairment, follow-up prevalence of all grades of impairment and baseline risk factors were examined by univariate and stepwise multiple logistic regression analysis.

Results. Overall, 8.4 year incidence of severe visual impairment was $1.94 \%$ and showed statistically significant univariate correlations with age at diagnosis, diabetes duration, systolic blood pressure, fasting blood glucose and cholesterol, insulin treatment and strongly with baseline retinopathy. Baseline retinopathy, systolic pressure and cholesterol were statistically significant in multivariable analysis. Differences between centres $(0.3 \%$ to $3.45 \%)$ were not significant. Ultimate prevalence of all grades of impairment differed between centres and within almost all of them was correlated in multivariable analysis with baseline retinopathy and proteinuria.

Conclusion/interpretation. Comparisons of incident severe visual impairment between centres are restricted by selective mortality, low incidence rates and relatively small numbers in each centre but before retinopathy, baseline systolic pressure and cholesterol predicted severe visual impairment. Followup prevalence of all degrees of impairment varied among centres and were associated with prior retinopathy and renal disease at baseline. [Diabetologia (2001) 44 [Suppl 2]: S31-S36]

Keywords Visual impairment, incidence, diabetes mellitus, prevalence, diabetic retinopathy, risk factors, multinational study.
In industrial societies more than $12 \%$ of new cases of blindness are attributable to diabetes and the risk of blindness is about 30 times higher in people with dia-

Corresponding author: Elisa T. Lee, $\mathrm{PhD}$, College of Public Health, University of Oklahoma Health Sciences Center, P.O. Box 26901, Oklahoma City, OK 73190, USA

* See reference 4 for list of investigators

Abbreviations: WHO MSVDD, World Health Organization Multinational Study of Vascular Disease in Diabetes; SVI, severe visual impairment. betes than in the general population $[1,2,3]$. The WHO Multinational Study of Vascular Disease in Diabetes (WHO MSVDD), designed to compare the vascular complications of diabetes in different ethnic groups using standardised methods, included an estimate of visual function in the baseline assessment [28]. This was repeated in the follow-up study [4], conducted at 10 of the original 14 centres, providing an opportunity to ascertain incidence and progression of visual impairment and its risk factors in these cohorts. 


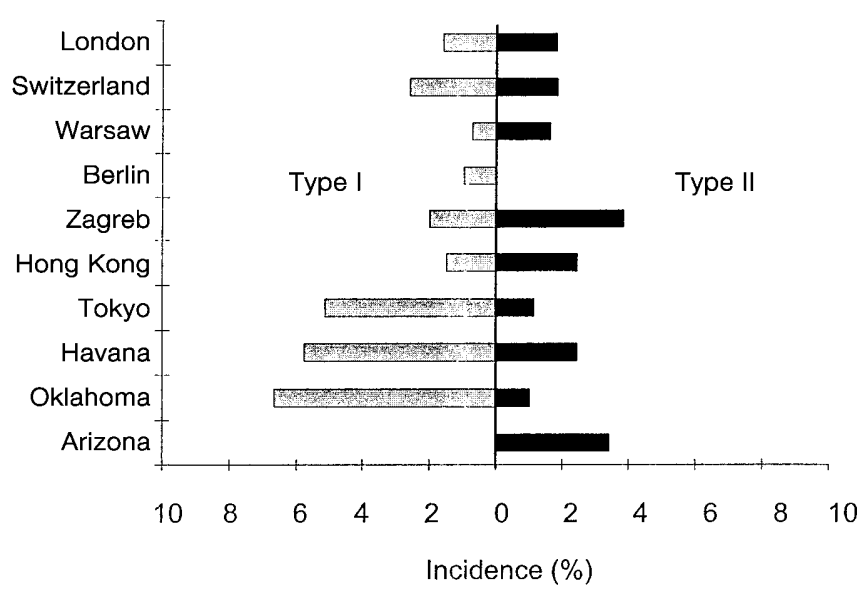

Fig. 1. Cumulative incidence of severe visual impairment by type of diabetes and centre

\section{Subjects and methods}

Assessment of the degree of visual impairment at follow-up was graded, as at baseline, from the responses to standard questions [5]. Of the original 4709 eligible patients in the 10 follow-up centres, $536(11.4 \%)$ had died, 305 (6.5\%) could not be traced and 856 failed to participate, with 3012 (77.9\% of traceable survivors) available for reassessment. This paper reports the incidence of severe visual impairment (SVI) during the follow-up period in the 2994 re-examined patients who were free of it at baseline. It also reports the prevalence of mild, moderate and severe visual disability present in all 3012 patients at re-examination and explores the association of baseline risk factors [4] with these findings.

Statistical analysis. Statistical analysis was done using SAS software (Carey, N. C., USA) [7]. Univariate analyses included chisquare statistic and Student's $t$ test. The rate ratios and $95 \%$ confidence intervals for incidence of severe visual impairment were estimated by baseline variables [8] using the MantelHaenszel test for bivariate analyses [9] and stepwise linear logistic regression for multivariate analyses [10]. A $p$ value of less than 0.05 was considered statistically significant.

\section{Results}

Incidence of severe visual impairment. Among the 3 868 traceable patients alive at follow-up, $23(0.59 \%)$ had SVI at baseline. Follow-up information was available for $2994(77.9 \%)$ of the rest and 851 $(22.1 \%)$ were lost to follow-up.

Severe visual impairment had developed in 58 patients, an incidence of $1.94 \%$ (Table 1). Proliferative diabetic retinopathy alone led to SVI in $21(36.2 \%)$, cataract alone in $10(17.2 \%)$, and both conditions in $9(15.5 \%)$. In 18 patients SVI was the consequence of diabetic maculopathy, in some associated with proliferative retinopathy, cataract, glaucoma or corneal opacity, and maculopathy probably contributed in others. Reported incidence of SVI was high in Zagreb $(3.45 \%)$, Arizona $(3.43 \%)$ and Havana $(2.97 \%)$ and low in Berlin $(0.30 \%)$ but differences between centres were not significant.

Incidence of SVI by centre and type of diabetes is shown in Figure 1. Differences in incidence between patients with Type I (insulin-dependent) diabetes mellitus and those with Type II (non-insulin-dependent) diabetes mellitus failed to achieve statistical significance in individual centres and in all centres (excluding Arizona where there were no patients with Type I diabetes) combined.

Because numbers at individual centres were small, univariate analysis of the relation between baseline variables and incident SVI was done using pooled data from all 10 centres, except for baseline fasting glucose concentrations for which 8 centres were pooled. Baseline factors associated with SVI (Table 2) included age at diagnosis, duration of diabetes, systolic blood pressure, fasting plasma glucose and cholesterol, type of treatment and baseline retinopathy (Fig. 2). No significant associations were found with sex, age, type of diabetes, diastolic blood pressure, BMI, smoking status, fasting triglycerides, renal disease or macrovascular disease at baseline.

Stepwise linear logistic regression analysis on the pooled data (Table 3 ) included the baseline variables: sex, age, duration of diabetes, systolic and diastolic

Table 1. Incidence of severe visual impairment by centre

\begin{tabular}{|c|c|c|c|c|c|c|}
\hline Centre & $\begin{array}{l}\text { Persons } \\
\text { at risk }\end{array}$ & $\begin{array}{l}\text { Can count } \\
\text { fingers only }\end{array}$ & $\begin{array}{l}\text { Light per- } \\
\text { ception only }\end{array}$ & $\begin{array}{l}\text { Totally } \\
\text { blind }\end{array}$ & Cases & $\begin{array}{l}\text { Total } \\
\text { Incidence (\%) }\end{array}$ \\
\hline London & 351 & 2 & 3 & 1 & 6 & 1.71 \\
\hline Switzerland & 370 & 0 & 2 & 6 & 8 & 2.16 \\
\hline Berlin & 332 & 0 & 0 & 1 & 1 & 0.30 \\
\hline Zagreb & 232 & 2 & 5 & 1 & 8 & 3.45 \\
\hline Hong Kong & 270 & 5 & 0 & 1 & 6 & 2.22 \\
\hline Oklahoma & 305 & 1 & 3 & 0 & 4 & 1.31 \\
\hline Arizona & 175 & 3 & 2 & 1 & 6 & 3.43 \\
\hline Total & 2994 & 23 & 21 & 14 & 58 & 1.94 \\
\hline
\end{tabular}




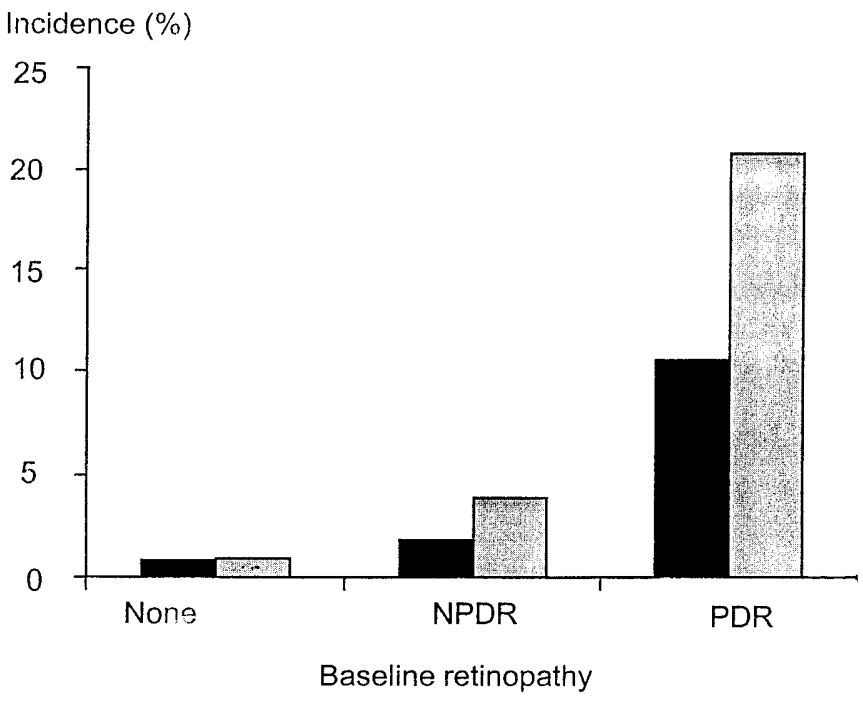

Fig. 2. Cumulative incidence of severe visual impairment by retinopathy at baseline in patients with Type I diabetes and Type II diabetes (NPDR: nonproliferative diabetic retinopathy; PDR: proliferative diabetic retinopathy), Type I diabetes Type II diabetes blood pressure, fasting glucose plasma, triglyceride and cholesterol, BMI, current smoking status, insulin use, any retinopathy, renal disease and macrovascular disease. Any retinopathy was associated with a greater than threefold increase in risk of developing SVI. Systolic blood pressure and plasma cholesterol were also significantly and independently associated. When baseline retinopathy was excluded from the model, duration of diabetes became the most important risk factor $(p<0.001)$. Systolic blood pressure $(p<0.001)$ and plasma cholesterol $(p=0.05)$ remained significant and baseline glucose emerged as significant $(p<0.05)$ in the 8 centre pool.

Prevalence of visual impairment at follow-up. The prevalence of different degrees of visual impairment at follow-up is shown by centre and type of diabetes (Figure 4). Overall, $9.43 \%$ of the patients had mild, $3.21 \%$ had moderate and $2.25 \%$ had severe impairment. These crude prevalence rates, varied significantly $(p<0.001)$ among centres with high total rates reported from the American Indian Oklahoma $(35.4 \%)$ and Pima $(26.3 \%)$ centres, contrasting with the lower European rates. The low rates reported from Berlin and Warsaw were influenced by selective loss to follow-up of visually defective patients. In To-

Table 2. Incidence of severe visual impairment by baseline variables in pooled data

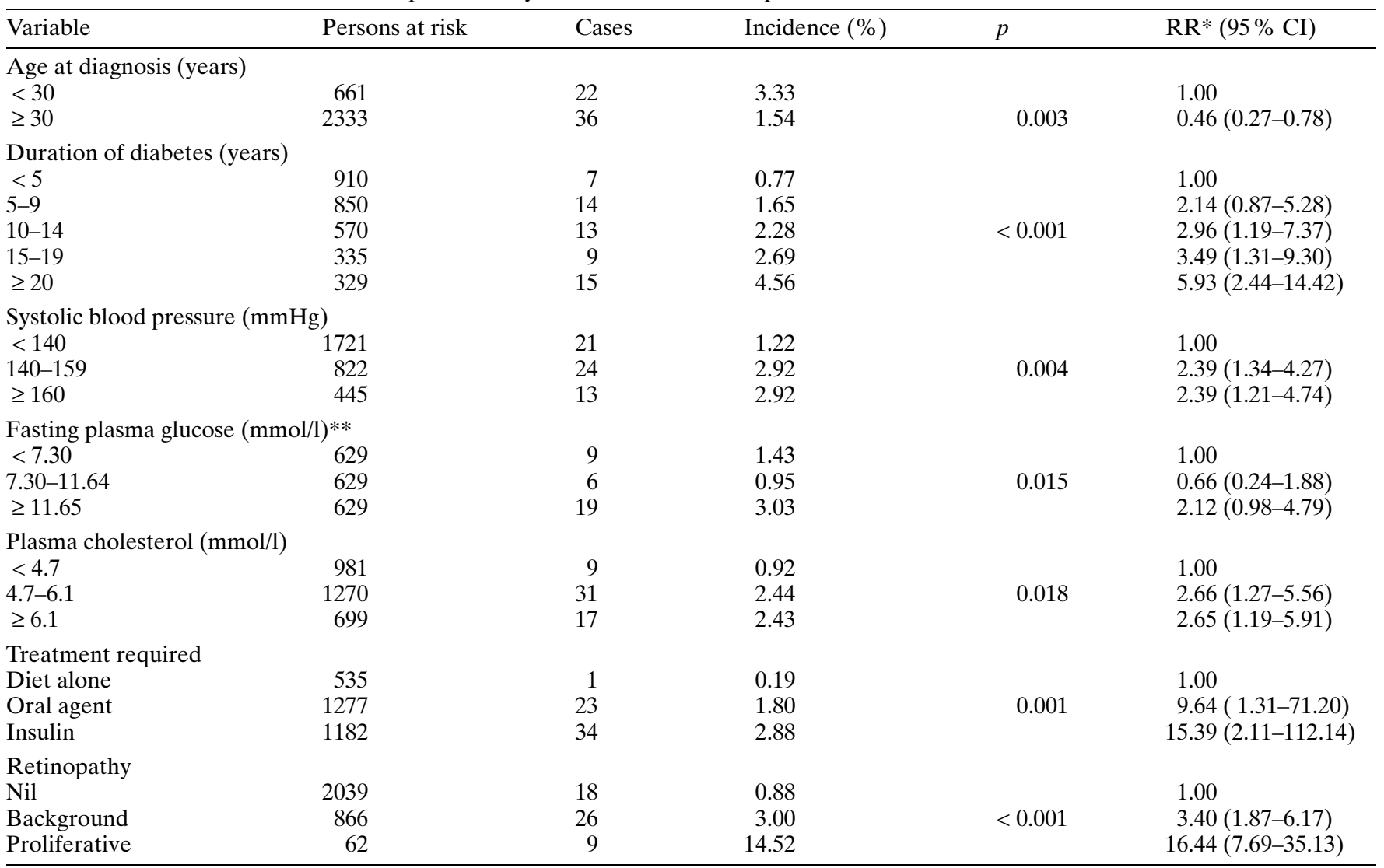

* rate ratio (95\% confidence interval) with first subgroup as reference group (1.00)

$* *$ in 8 centres 
Table 3. Baseline risk factors associated with severe visual impairment at follow-up from stepwise logistic regression analysis using pooled data

\begin{tabular}{lllll}
\hline $\begin{array}{l}\text { Baseline } \\
\text { Variables }\end{array}$ & $\begin{array}{l}\text { Regression } \\
\text { Coefficient }\end{array}$ & $\begin{array}{l}\text { Standard } \\
\text { Error }\end{array}$ & $\begin{array}{l}p \\
\text { value }\end{array}$ & OR (95\% CI) \\
\hline Retinopathy (0-no,1-yes) & 1.257 & 0.331 & $<0.001$ & $3.51(1.84-6.72)$ \\
Systolic blood pressure* & 0.177 & 0.083 & 0.007 & $1.19(1.01-1.41)$ \\
Plasma cholesterol (mm/1) & 0.175 & 0.088 & 0.028 & $1.19(1.01-1.41)$ \\
\hline
\end{tabular}

${ }^{\text {a }}$ odds ratio and its $95 \%$ confidence interval.

*per $10 \mathrm{mmHg}$ change

Table 4. Odds ratios for baseline variables with any visual impairment by centre from stepwise logistic regression analysis

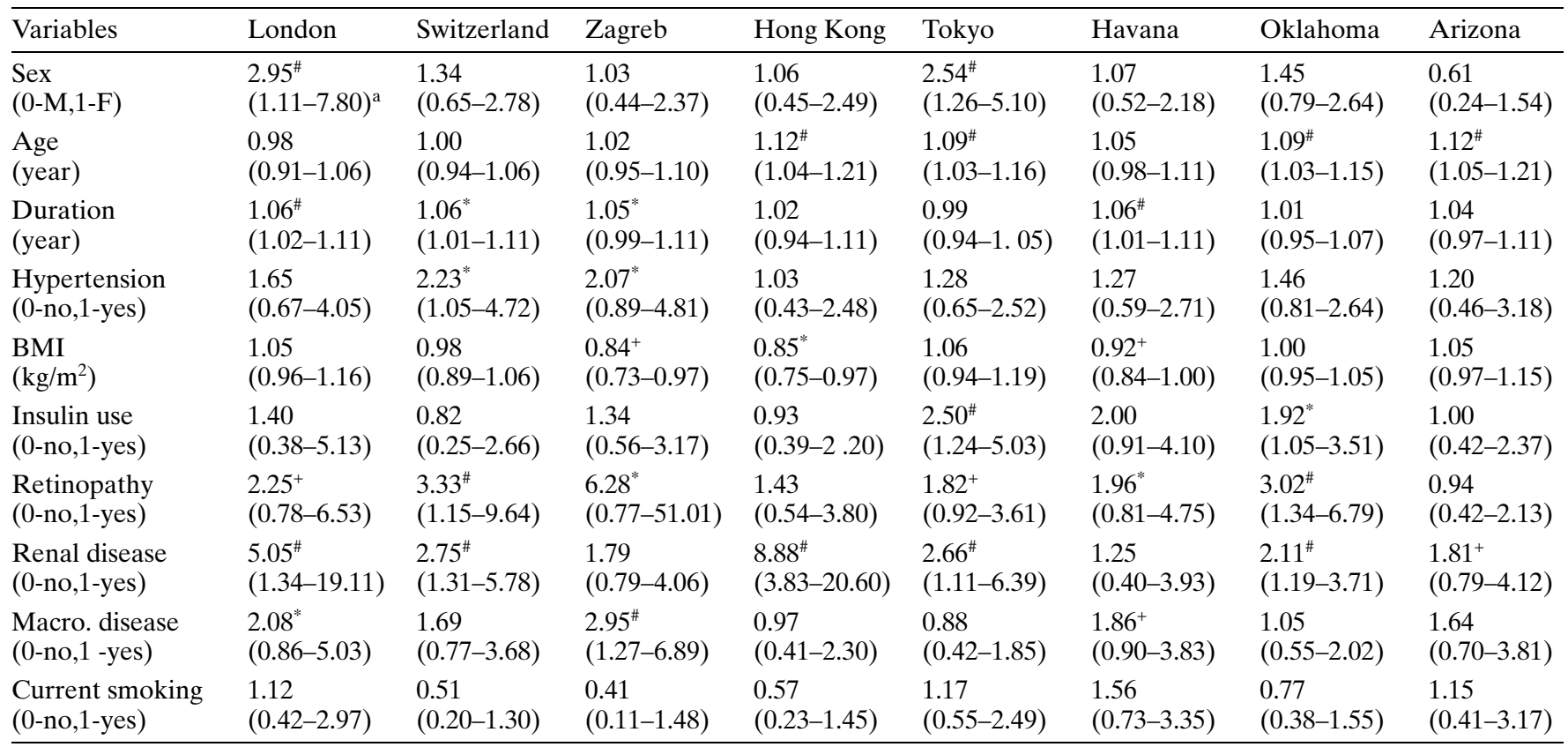

${ }^{\#} \mathrm{p}<0.01,{ }^{*} \mathrm{p}<0.05,{ }^{+} \mathrm{p}<0.10,{ }^{\mathrm{a}} 95 \%$ confidence interval; Macro. disease:macrovascular disease.

kyo and Havana, the prevalence of visual impairment reported by patients with Type I diabetes was almost twice that reported by patients with Type II diabetes $(p<0.05$ for each).

Stepwise linear logistic regression analysis in the 8 centres with adequate numbers with any visual impairment included baseline variables: sex, age, duration of diabetes, hypertension status, BMI, current smoking status, insulin use, fasting plasma glucose, and any retinopathy, renal disease and macrovascular disease. Baseline retinopathy and renal disease were significantly associated in almost all centres (Table 4) but other factors were less universally related. Current smoking was not significant at any centre.

\section{Discussion}

Diabetes remains a leading cause of blindness and lesser visual impairment in working-aged adults, particularly in industrial societies. In the United States it was estimated that $12 \%$ of all new blindness was at- tributable to diabetic retinopathy [1], a proportion comparable to that reported from analysis of blindness registrations in the United Kingdom [11,12]. In these societies adults with diabetes are at a 25 to 30 times greater risk of blindness than the general adult population. There is a number of reports on prevalence and incidence of visual impairment in diabetes $[1,11-28]$ but there are no multinational comparisons. A comprehensive review of diabetes and its complications [13], retrieved from the world literature, provided data on the varying estimates of prevalence of retinopathy but did not include visual disability.

The subjective measures of visual dysfunction reported here were selected as suitable for the wide range of centres collaborating in this study but were inevitably influenced by observer variation and bias. These findings can thus be presented only as a broad representation of the changing visual status of the multinational cohorts reported. The baseline prevalence of SVI in the patients originally constituting the 10 follow-up centres was $0.89 \%$ [28]. During the 


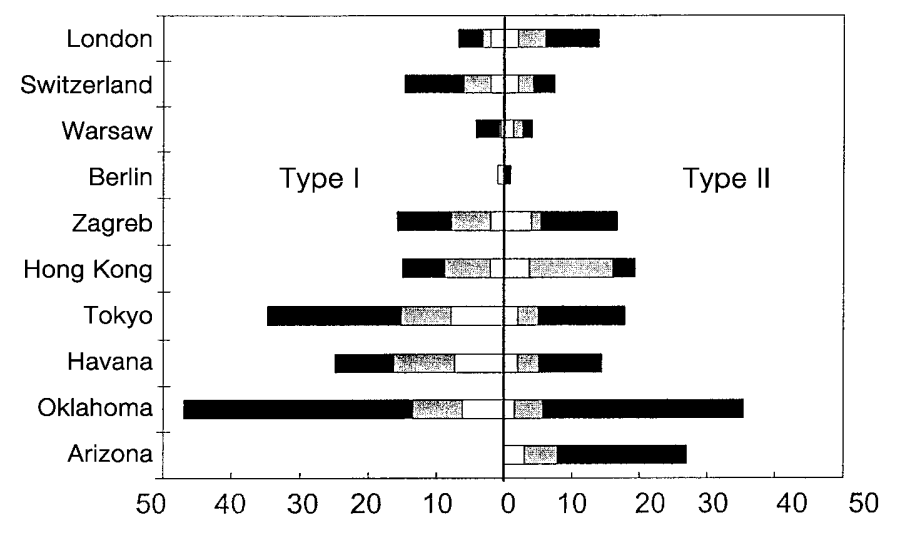

Prevalence (\%)

Fig.3. The prevalence of visual impairment at follow-up by type of diabetes and centre. Severe $\square$; Moderate $\square$; Mild

follow-up, $1.94 \%$ of those free of SVI at baseline entered this category, raising the overall prevalence $(p<0.001)$ to $2.25 \%$. This is likely to be a substantial underestimate of the true incidence, however. Others have described the greatly increased mortality risk of those with visual impairment $[29,30]$. Of the 42 with SVI at baseline in this study, 19 (45.2\%) had died by the time of follow-up compared with $536(11.4 \%)$ of the original cohort of 4709. Many of the other 517 decedents could have become seriously visually impaired by the time of death; at baseline they had longer duration of diabetes, higher systolic blood pressures and higher plasma cholesterol than the survivors, all risk factors for SVI. The 851 non-participating survivors ( $22.1 \%$ of the cohort) also had longer diabetes duration and higher arterial pressures at baseline than the participants.

The cumulative SVI incidence of $1.94 \%$ over a mean of 8.4 years is lower than that reported over 4 years in the older onset group of the Wisconsin (WESDR) study [15], namely $3.2 \%$ and $2.7 \%$ for those taking insulin and those not taking insulin respectively. The annual incidence of blindness fell substantially in the subsequent 6 years of this study. Our criteria of SVI were probably more rigorous than those of WESDR (VA of 20/200 or less in the better eye).

The variation in incidence of SVI among WHO MSVDD centres was not significant and was comparable with the variation among other published incidence rates [11,12,14-22,25-27]. Its distribution was, however, broadly consistent with the relative incidence of ophthalmoscopically ascertained retinopathy among them [4]. Prevalence rates of any visual impairment at follow-up were higher and differences between centres significant $(p<0.01)$.

Retinopathy at baseline was a highly significant predictor of SVI, a correlation well documented else- where [15-21,27,32,33]. Patients with baseline nonproliferative retinopathy were 3 times more likely to develop SVI and those with proliferative retinopathy 16 times, than those free of retinopathy at baseline. Systolic blood pressure, associated with baseline retinopathy [28, 34] and retinopathy progression [6], was also a powerful independent predictor of SVI. The relation between arterial pressure, retinopathy and the potential for visual impairment has been noted in many other studies $[22,31,35,36]$. Most recently, tight control of raised blood pressure in Type II diabetes has been shown to slow the progression of retinopathy and reduce the need for photocoagulation compared with less tight pressure control [41]. Renal disease, strongly associated with retinopathy and increased arterial pressure could contribute to the association of SVI with baseline blood cholesterol, significant in both univariate and multivariate analyses and reported elsewhere [23, 24, 27].

As in other reports [14, 17, 25-27], age at diagnosis and diabetes duration were also found to be significant univariate predictors of visual impairment. Estimates of diabetes duration are not likely to be reliable in patients with Type II diabetes. This along with the increasing role of non-diabetic eye disease in older people makes it difficult to interpret differences in visual impairment between Type I and Type II diabetes. In this study, women had a higher prevalence of visual impairment than men in London and Tokyo present after adjusting for other risk factors and an increased risk of diabetic blindness in women has been noted in some earlier studies [17, 25, 26].

Patients treated with insulin were at greater risk for incident SVI in univariate analysis of pooled data (Table 2) and, by multivariate analysis, for any visual impairment in the Tokyo and Oklahoma cohorts [15, 19,20]. Insulin use is, however, a marker for more severe degrees of hyperglycaemia. Furthermore, in some centres, visual disorder could be an indication for starting insulin treatment. In the 8 centres where baseline fasting glucose was measured, incident SVI was twice as high in those in the top third of the glucose distribution as in the lower two thirds. The importance of hyperglycaemia in the incidence of retinopathy and the progression of mild to moderate retinopathy was highlighted by DCCT [38] though its late stages are likely to be increasingly influenced by other determinants $[39,40]$ particularly by the retinovascular damage itself.

\section{References}

1. Klein R, Klein BEK (1995) Vision disorders in diabetes. In: Diabetes in America. 2nd edn. NIH Publication No. 95-1468, Washington, D. C. pp 293-305

2. Kohner EM, Porta M (1990) Diabetic retinopathy. In: Alberti KGMM, Krall LP (ed.) Diabetes Annual 5, Elsevier, Amsterdam pp 273-300 
3. Fukuda M (1994) Classification and treatment of diabetic retinopathy. Diabetes Res Clin Pract 24: S171-S176

4. Lee ET, Keen H, Bennett PH, Fuller J, Lu M, the WHO Multinational Study Group (2001) Follow-up of the WHO multinational study of vascular disease in diabetes: General description and morbidity. Diabetologia 44 [Supp 2]: S3-S 13

5. Jarrett RJ, Keen H, Grabaukas V (1979) The WHO multinational study of vascular disease in diabetes: 1 . General description. Diabetes Care 2: 175-186

6. Keen H, Lee ET, Miki E, Bennett PH, Lu M, the Multinational Study Group (2001) The appearance of retinopathy and progression to proliferative retinopathy: the WHO Multinational Study of Vascular Disease in Diabetes. Diabetologia 44 [Supp 2]: S 22-S30

7. SAS User's Guide: Statistics. (1990) Version 6.04, Cary, NC, SAS Instit

8. Morris JA, Gardner MJ (1988) Calculating confidence intervals for relative risks (odds ratios) and standardized ratios and rates. BMJ 196: 1313-1316

9. Mantel N, Haenszel W (1959) Statistical aspects of analysis of data from retrospective studies of disease. J Natl Cancer Inst 22: 719-748

10. SAS Technical report P-200 (1990). SAS/STAT Software: CALIS and LOGISTIC procedures, Release 6.04, SAS Institute Inc., Cary

11. Bruce I, McKennell A, Walker E (1991) Blind and partial sighted adults in Britain. The RNIB Survey 1991. HMSO, London

12. Kohner E, Allwinkle J, Andrews J et al. (1996) Report of the visual handicap group. Diabet Med 13 [Suppl 4]: S13S26

13. Amos AF, McCarthy DJ, Zimmet P (1997) The rising global burden of diabetes and its complications: estimates and projections to the year 2010. Diabet Med 14 [Suppl S5] S7S85

14. Sjolie AK, Green A (1987) Blindness in insulin-treated diabetic patients with age at onset $<30$ years. J Chronic Dis 40: $215-220$

15. Moss SE, Klein R, Klein BEK (1988) The incidence of vision loss in a diabetic population. Ophthalmology 95: 1340-1348

16. Caird FI, Burditt AF, Draper GJ (1968) Diabetic retinopathy: a further study of prognosis for vision. Diabetes 17 : 121-123

17. Deckert T, Simonsen SE, Poulsen JE (1967) Prognosis of proliferative diabetic retinopathy in juvenile diabetics. Diabetes 16: 728-733

18. Dwyer MS, Melton LJ $3^{\text {rd }}$, Ballard DJ, Palumbo PJ, Trautmann JC, Chu CP (1985) Incidence of diabetic retinopathy and blindness: A population-based study in Rochester, Minnesota. Diabetes Care 8: 316-322

19. Nielsen NV (1984) Diabetic retinopathy I. The course of retinopathy in insulin-treated diabetics. A one year epidemiological cohort study of diabetes mellitus. The island of Falster, Denmark. Acta Ophthalmol Scand 62: 256-265

20. Nielsen NV (1984) Diabetic retinopathy II. The course of retinopathy in diabetics treated with oral hypoglycemic agents and diet regime alone. A one year epidemiological cohort study of diabetes mellitus. The island of Falster, Denmark. Acta Ophthalmol Scand 62: 266-273

21. Rand LI, Prud'homme GJ, Ederer F, Canner PL, the Diabetic Retinopathy Study Research Group (1985) Factors influencing the development of visual loss in advanced diabetic retinopathy: Diabetic Retinopathy Study (DRS) Report No. 10. Invest Ophthalmol Vis Sci 26: 983-991
22. Lee ET, Lee VS, Lu M, Russell D (1992) Development of proliferative retinopathy in NIDDM: A follow-up study of American Indians in Oklahoma. Diabetes 41: 359-367

23. Nelson RG, Wolfe JA, Horton MB, Pettitt DJ, Bennett $\mathrm{PH}$, Knowler WC (1989) Proliferative retinopathy in NIDDM: Incidence and risk factors in Pima Indians. Diabetes 38: $435-440$

24. Kostraba JN, Klein R, Dorman JS et al. (1991) The Epidemiology of Diabetes Complications Study IV. Correlates of diabetic background and proliferative retinopathy. Am J Epidemiol 133: 381-391

25. Operational Research Department, National Society to Prevent Blindness (1980) Vision problem in the U.S.: A Statistical Analysis. National Society to Prevent Blindness, New York, pp 1-46

26. Kahn HA, Hill R (1974) Blindness caused by diabetic retinopathy. Am J Ophthalmol 78: 58-67

27. Klein R, Klein BEK, Moss SE (1984) Visual impairment in diabetes. Ophthalmol 91: 1-9

28. Diabetes Drafting Group (1985) Prevalence of small vessel and large vessel disease in diabetic patients from 14 centres. The World Health Multinational Study of Vascular Disease in Diabetes. Diabetologia 28: 615-640

29. Rogot E, Goldberg ID, Goldstein H (1987) Survivorship and causes of death among the blind. J Chronic Dis 19: 179-197

30. Klein R, Moss SE, Klein BEK, DeMets DL (1989) Relation of ocular and systemic factors to survival in diabetes. Arch Intern Med 149: 266-272

31. Lee ET, Lee VS, Kingsley RM et al. (1992) Diabetic retinopathy in Oklahoma Indians with NIDDM: incidence and risk factors. Diabetes Care 15: 1620-1627

32. Valone JA Jr, McMeel JW, Franks EP (1981) Unilateral proliferative diabetic retinopathy. II. Clinical course. Arch Ophthalmol 99: 1362-1366

33. Berkow JW, Shugarman RG, Maumenee AE, Patz A (1965) A retrospective study of blind diabetic patients. JAMA 193: 867-870

34. Jarrett RJ, Keen H (1979) The WHO multinational study of vascular disease in diabetes: 3 . Microvascular disease. Diabetes Care 2: 196-201

35. Teuscher A, Schnell H, Wilson PWF (1988) Incidence of diabetic retinopathy and relationship to baseline plasma glucose and blood pressure. Diabetes Care 11: 246-251

36. Knowler WC, Bennett PH, Ballantine EJ (1980) Increased incidence of retinopathy in diabetics with elevated blood pressure. N Engl J Med 302: 645-650

37. Dornan TL, Carter RD, Bron AJ, Turner RC, Mann JI (1982) Low density lipoprotein cholesterol: A association with severity of diabetic retinopathy. Diabetologia 22: 167-170

38. The DCCT Research Group (1993) The effect of intensive treatment of diabetes on the development and progression of long-term complications in insulin-dependent diabetes mellitus. New Engl J Med 329: 977-986

39. Lawson PM, Champion MC, Canny C et al. (1982) Continuous subcutaneous insulin infusion does not prevent progression of proliferative and pre-proliferative retinopathy. Br J Ophthalmol 66: 762-766

40. Pucklin JE, Tamborlane WV, Felig P et al. (1982) Influence of long-term insulin infusion pump treatment of type 1 diabetes on diabetic retinopathy. Ophthalmology 89: 735-747

41. UK Prospective Diabetes Study, (1998) Tight blood pressure control and risk of macrovascular and microvascular complications in type 2 diabetes: UKPDS 38. BMJ 317: 703-713 